\title{
Propofol attenuates the increase of sonographic optic nerve sheath diameter during robot-assisted laparoscopic prostatectomy: a randomized clinical trial
}

Jihion Yu' ${ }^{1}$, Jun Hyuk Hong ${ }^{2}$, Jun-Young Park', Jai-Hyun Hwang ${ }^{1}$, Seong-Sik Cho ${ }^{3^{*}}$ and Young-Kug Kim ${ }^{1^{*}}$ (D)

\begin{abstract}
Background: Robot-assisted laparoscopic prostatectomy (RALP) requires pneumoperitoneum and the Trendelenburg position to optimize surgical exposure, which can increase intracranial pressure (ICP). Anesthetic agents also influence ICP. We compared the effects of propofol and sevoflurane on sonographic optic nerve sheath diameter (ONSD) as a surrogate for ICP in prostate cancer patients who underwent RALP.

Methods: Thirty-six patients were randomly allocated to groups receiving propofol (propofol group, $n=18$ ) or sevoflurane (sevoflurane group, $\mathrm{n}=18$ ) anesthesia. The ONSD was measured $10 \mathrm{~min}$ after induction of anesthesia in the supine position (T1); $5 \mathrm{~min}$ (T2), $30 \mathrm{~min}$ (T3), and $60 \mathrm{~min}$ (T4) after establishing pneumoperitoneum and the Trendelenburg position; and at the end of surgery after desufflation in the supine position (T5). Respiratory and hemodynamic variables were also evaluated.

Results: The ONSD was significantly different between the propofol group and the sevoflurane group at T4 (5.27 \pm $0.35 \mathrm{~mm}$ vs. $5.57 \pm 0.28 \mathrm{~mm}, P=0.007$ ), but not at other time points. The ONSDs at T2, T3, T4, and T5 were significantly greater than at $\mathrm{T} 1$ in both groups (all $P<0.001$ ). Arterial carbon dioxide partial pressure, arterial oxygen partial pressure, peak airway pressure, plateau airway pressure, systolic blood pressure, pulse pressure variation, body temperature and regional cerebral oxygen saturation, except heart rate, were not significantly different between the two groups.

Conclusions: The ONSD was significantly lower during propofol anesthesia than during sevoflurane anesthesia 60 min after pneumoperitoneum and the Trendelenburg position, suggesting that propofol anesthesia may help minimize ICP changes in robotic prostatectomy patients.
\end{abstract}

Trial registration: Clinicaltrials.gov identifier: NCT03271502. Registered August 31, 2017.

Keywords: Propofol, Sevoflurane, Sonographic optic nerve sheath diameter, Robot-assisted laparoscopic prostatectomy

\section{Background}

Since robot-assisted laparoscopic prostatectomy (RALP) was first reported by Binder and Kramer in 2001, it has become the dominant surgical approach for prostate cancer treatment [1]. RALP has many benefits related to

\footnotetext{
* Correspondence: sscho@hallym.or.kr; kyk@amc.seoul.kr

${ }^{3}$ Department of Occupational and Environmental Medicine, Hallym University Sacred Heart Hospital, 22, Kwanpying-ro 170-gil, Dongan-gu, Anyang 14068, Republic of Korea

${ }^{1}$ Department of Anesthesiology and Pain Medicine, Asan Medical Center, University of Ulsan College of Medicine, 88, Olympic-ro 43-gil, Songpa-gu, Seoul 05505, Republic of Korea

Full list of author information is available at the end of the article
}

oncological outcomes and perioperative complications when compared to open surgery. These benefits include more precise manipulation of vessels and nerves; decreased blood loss; reduced surgical time, length of hospital stay, and postoperative pain; and improved quality of life [2, 3]. However, RALP requires carbon dioxide pneumoperitoneum and a steep Trendelenburg position to optimize surgical exposure. These conditions increase intracranial pressure (ICP) $[4,5]$. Increased ICP and the resulting decreased cerebral perfusion pressure are associated with postoperative neurological complications such as cerebral ischemia and cerebrovascular

(c) The Author(s). 2018 Open Access This article is distributed under the terms of the Creative Commons Attribution 4.0 International License (http://creativecommons.org/licenses/by/4.0/), which permits unrestricted use, distribution, and 
disorders [6]. Therefore, it is necessary to minimize intraoperative ICP changes in robotic prostatectomy patients in whom ICP may increase beyond the normal range.

Anesthetic agents can influence ICP during surgery. In propofol anesthesia, a dose-related decrease in cerebral blood flow, cerebral metabolic rate, and ICP have been reported $[7,8]$. Sevoflurane is a cerebral vasodilator with the potential to increase cerebral blood flow, cerebral blood volume, and ICP in a dose-dependent manner $[9,10]$. However, the effects of anesthetics on ICP during carbon dioxide pneumoperitoneum and a steep Trendelenburg position during RALP have not been studied.

The purpose of this study was to compare the effects of propofol and sevoflurane on ICP in prostate cancer patients who underwent RALP. We evaluated the sonographic optic nerve sheath diameter (ONSD) as a surrogate for ICP [11].

\section{Methods}

This randomized clinical trial included 36 patients who underwent RALP at Asan Medical Center during September 2017. Ethical approval for this study was provided by the Institutional Review Board at Asan Medical Center, Seoul, Republic of Korea (approval no. 20171011) on August 24, 2017. This study was registered with ClinicalTrials.gov (NCT03271502). Written informed consent was obtained from all patients.

\section{Patients}

Patients who were scheduled for an elective RALP using the da Vinci ${ }^{\text {tw }}$ robot system (Intuitive Surgical, Inc., Sunnyvale, CA, USA) were enrolled in this study. Patients with a history of cerebrovascular disease, those who refused to participate, and those younger than 20 or older than 79 were excluded.

\section{Randomization and interventions}

Patients were randomly assigned to two groups using web-based randomization software (Random Allocation Software version 1.0, Isfahan University of Medical Sciences, Isfahan, Iran) [12]. We used block randomization with random block sizes of 6 and an allocation ratio of 1:1. One investigator kept sealed envelopes labeled with sequential study numbers, which were opened just before induction of anesthesia. The investigator performed total intravenous anesthesia with propofol (propofol group) or inhalation anesthesia with sevoflurane (sevoflurane group) according to a randomized table. The ventilator screen and the syringes of medications are concealed. We also prepared concealed syringes of normal saline in the sevoflurane group, indistinguishable from the outside. The investigators who measured the parameters did not know the method of anesthesia. The investigators who analyzed the data did not know the group. The investigators were blinded to the allocation of treatment until data analysis was complete.

\section{Study protocol}

After routine hemodynamic monitoring including electrocardiogram, non-invasive blood pressure, pulse oximetry, bispectral index (Aspect Medical Systems, Inc., Newton, MA, USA) and regional cerebral oxygen saturation using near-infrared spectroscopy (IVOS $5100^{\mathrm{mm}}$, Somanetics Corp., Troy, MI, USA) were performed, preoxygenation was performed by administering $8 \mathrm{~L} / \mathrm{min}$ of oxygen via facial mask before induction of anesthesia. Patients were randomly allocated into one of two groups according to a random table: the propofol group or the sevoflurane group. In the propofol group, propofol and remifentanil were infused continuously using a target-controlled infusion system to induce and maintain anesthesia. Propofol was adjusted to effect site target concentration of $1.5-3 \mu \mathrm{g} / \mathrm{mL}$ according to Marsh et al. [13]. Remifentanil was adjusted to effect site target concentration of $2-10 \mathrm{ng} / \mathrm{mL}$ according to Minto et al. [14]. In the sevoflurane group, anesthesia was induced with $1.5 \mathrm{mg} / \mathrm{kg}$ propofol and maintained with $1-2$ vol\% sevoflurane and continuous infusion of remifentanil into the effect site to a target concentration of 2-10 ng/mL, according to Minto et al. [14].

In the both groups, $0.6 \mathrm{mg} / \mathrm{kg}$ of rocuronium was administered for muscle relaxation during anesthetic induction. In addition, $0.1-0.2 \mathrm{mg} / \mathrm{kg}$ of rocuronium was intermittently administered during surgery. During the operation, propofol, sevoflurane, and remifentanil were adjusted to maintain a bispectral index score of 40-60, and arterial blood pressure and heart rate within $20 \%$ of the baseline. An arterial line was placed in the radial artery to continuously monitor the arterial blood pressure. Mechanical ventilation was set to volume control mode and a tidal volume of $8 \mathrm{~mL} / \mathrm{kg}$ of ideal body weight. A respiratory rate of $10-20$ breaths/min was adjusted to maintain an end-tidal carbon dioxide concentration of 30-35 mmHg. Positive end expiratory pressure was not applied. Oxygen at 50\% was supplied using medical air. Plasma solution A (CJ Pharmaceutical, Seoul, Korea) as a crystalloid fluid was administered at a rate of $2-4 \mathrm{~mL} /$ $\mathrm{kg} / \mathrm{hr}$.

\section{Measurement}

The ONSD was measured by investigators trained in ocular sonography. Measurements were performed in the transverse and sagittal planes of both eyes; the final ONSD value was the average of the 4 measured values. A 7.5- $\mathrm{MHz}$ linear probe was used for ONSD measurement, which was measured at 5 time points. The ONSD 
was measured at $10 \mathrm{~min}$ after anesthetic induction in the supine position (T1), 5 min after establishing carbon dioxide pneumoperitoneum and a steep Trendelenburg position (45-degree incline) (T2), $30 \mathrm{~min}$ after establishing carbon dioxide pneumoperitoneum and a steep Trendelenburg position (T3), $60 \mathrm{~min}$ after establishing carbon dioxide pneumoperitoneum and a steep Trendelenburg position (T4), and at the end of surgery after desufflation of pneumoperitoneum in the supine position (T5).

At each time point, we also measured the following variables: arterial carbon dioxide partial pressure $\left(\mathrm{PaCO}_{2}\right)$, arterial oxygen partial pressure $\left(\mathrm{PaO}_{2}\right)$, peak airway pressure, plateau airway pressure, systolic blood pressure, heart rate, pulse pressure variation, body temperature and regional cerebral oxygen saturation.

The duration of hospital stay and postoperative neurologic complications such as stroke, transient ischemic attack, and reversible neurologic deficit were evaluated.

\section{Statistical analysis}

In the previous study, the mean \pm standard deviation of ONSD was $4.9 \pm 0.4 \mathrm{~mm}$ during pneumoperitoneum and the Trendelenburg position under sevoflurane anesthesia [15]. Assuming that the ONSD of propofol anesthesia was reduced by $10 \%$ compared with the ONSD of sevoflurane anesthesia, the mean difference of the ONSD between propofol anesthesia and sevoflurane anesthesia was $0.49 \mathrm{~mm}$. The sample size was calculated to be at least 16 subjects for each group, using a power of $90 \%$ and at a significance level of $P<0.05$. Considering a dropout rate of $10 \%$, the total number of patients was 36 , or 18 patients per group. All data are expressed as the mean \pm standard deviation or as number (\%). Comparisons between the groups were performed using a Student's t-test, Mann-Whitney U test, chi-square test, or Fisher's exact test, as appropriate. A two-way repeated measures analysis of variance with Bonferroni post-testing was used to compare the ONSD, respiratory variables, and hemodynamic variables within and between the two groups. $P$ values $<0.05$ were considered significant. All statistical analyses were performed using IBM SPSS Statistics for Windows, Version 22.0 (IBM Corp., Armonk, NY, USA).

\section{Results}

During the study period, 45 patients were screened. Three patients were excluded due to a history of cerebrovascular disease and six patients refused to participate. A total of 36 patients were included and were randomly allocated to either the propofol group or the sevoflurane group (Fig. 1). Demographic and intraoperative data were not significantly different between the two groups (Table 1).

The ONSDs of the two groups are shown in Table 2. The ONSDs were not significantly different between the two groups $10 \mathrm{~min}$ after anesthetic induction in the supine position (T1) or 5 min after establishing carbon dioxide pneumoperitoneum and steep Trendelenburg position (T2). However, 30 min after carbon dioxide pneumoperitoneum and steep Trendelenburg position (T3), the ONSD tended to differ between the groups (5.22 \pm

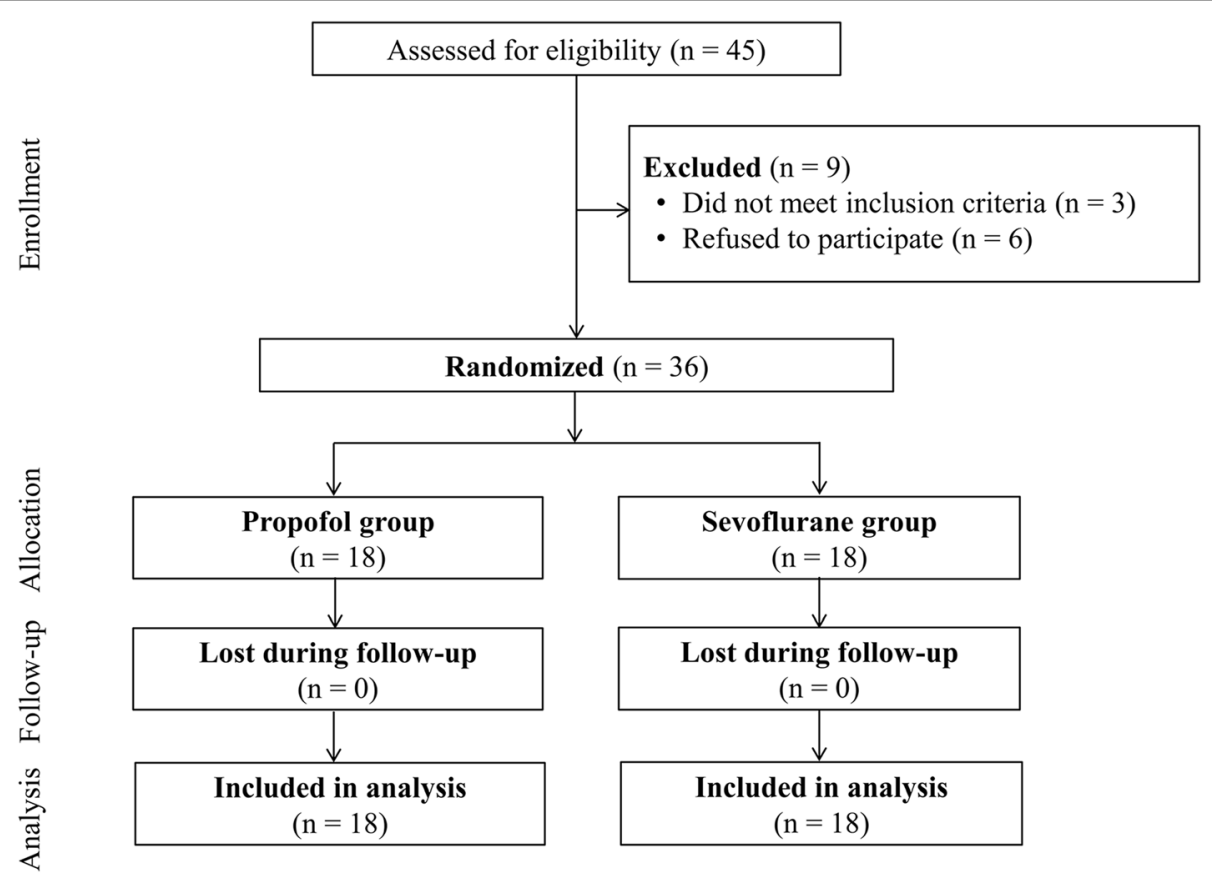

Fig. 1 Study flow diagram 
Table 1 Demographic and intraoperative data

\begin{tabular}{|c|c|c|c|c|}
\hline Variables & All patients $(n=36)$ & Propofol group $(n=18)$ & Sevoflurane group $(n=18)$ & $P$ value \\
\hline Age (yr) & $64.8 \pm 7.6$ & $66.1 \pm 7.2$ & $63.6 \pm 7.9$ & 0.339 \\
\hline Weight (kg) & $71.1 \pm 8.7$ & $72.3 \pm 6.5$ & $69.8 \pm 10.6$ & 0.399 \\
\hline Height (cm) & $165.8 \pm 6.0$ & $166.0 \pm 4.0$ & $165.6 \pm 7.6$ & 0.868 \\
\hline Body mass index $\left(\mathrm{kg} / \mathrm{m}^{2}\right)$ & $25.8 \pm 2.3$ & $26.1 \pm 1.9$ & $25.4 \pm 2.7$ & 0.410 \\
\hline Hypertension & $16(44.4 \%)$ & $8(44.4 \%)$ & $8(44.4 \%)$ & 1.000 \\
\hline Diabetes mellitus & $4(11.1 \%)$ & $3(16.7 \%)$ & $1(5.6 \%)$ & 0.289 \\
\hline \multicolumn{5}{|c|}{ Preoperative laboratory values } \\
\hline Hemoglobin (g/dL) & $14.2 \pm 0.9$ & $13.9 \pm 0.9$ & $14.5 \pm 0.9$ & 0.060 \\
\hline Albumin (g/dL) & $3.88 \pm 0.24$ & $3.93 \pm 0.18$ & $3.83 \pm 0.28$ & 0.211 \\
\hline Creatinine $(\mathrm{mg} / \mathrm{dL})$ & $0.90 \pm 0.22$ & $0.92 \pm 0.28$ & $0.87 \pm 0.13$ & 0.478 \\
\hline Operation time (min) & $147.1 \pm 23.4$ & $149.9 \pm 20.2$ & $144.2 \pm 26.6$ & 0.472 \\
\hline Anesthesia time (min) & $187.8 \pm 22.9$ & $190.6 \pm 18.9$ & $184.9 \pm 26.6$ & 0.461 \\
\hline Crystalloid amount (mL) & $1273.6 \pm 318.8$ & $1227.8 \pm 351.1$ & $1319.4 \pm 285.5$ & 0.396 \\
\hline
\end{tabular}

Data are presented as mean \pm standard deviation or as number (\%)

* indicates comparison between the propofol group and the sevoflurane group

$0.34 \mathrm{~mm}$ vs. $5.42 \pm 0.36 \mathrm{~mm}, P=0.096$ ). Sixty minutes after carbon dioxide pneumoperitoneum and a steep Trendelenburg position (T4), the ONSD was significantly different between the two groups $(5.27 \pm 0.35 \mathrm{~mm}$ vs. 5.57 $\pm 0.28 \mathrm{~mm}, P=0.007$ ) (Fig. 2). There were significant increases in the ONSDs in both groups at T2, T3, and T4 compared to T1 (propofol group: all $P<0.001$; sevoflurane group: all $\mathrm{P}<0.001)$. During pneumoperitoneum and the Trendelenburg position at T2, T3, and T4, sonographic ONSDs tended to increase continuously (Table 2).

There were no significant differences in $\mathrm{PaCO}_{2}, \mathrm{PaO}_{2}$, peak airway pressure, plateau airway pressure, systolic blood pressure, pulse pressure variation, and body temperature between the groups (Fig. 3). However, heart rate was higher at $\mathrm{T} 3, \mathrm{~T} 4$, and $\mathrm{T} 5$ in the sevoflurane group than in the propofol group (T3, $P=0.018$; T4, $P=0.006$; $\mathrm{T} 5, P=0.005)$. In addition, there were no significant differences in regional cerebral oxygen saturation between the

Table 2 Sonographic optic nerve sheath diameters in the propofol group and the sevoflurane group during robot-assisted laparoscopic prostatectomy

\begin{tabular}{llll}
\hline Time point & Propofol group $(\mathrm{mm})$ & Sevoflurane group $(\mathrm{mm})$ & P value \\
\hline T1 & $4.75 \pm 0.37$ & $4.74 \pm 0.42$ & 0.942 \\
T2 & $5.09 \pm 0.36$ & $5.22 \pm 0.41$ & 0.319 \\
T3 & $5.22 \pm 0.34$ & $5.42 \pm 0.36$ & 0.096 \\
T4 & $5.27 \pm 0.35$ & $5.57 \pm 0.28$ & 0.007 \\
T5 & $5.18 \pm 0.37$ & $5.29 \pm 0.41$ & 0.403 \\
\hline
\end{tabular}

Data are presented as mean \pm standard deviation. $T 1=10 \mathrm{~min}$ after anesthetic induction in the supine position, $T 2=5 \mathrm{~min}$ after establishing carbon dioxide pneumoperitoneum and a steep Trendelenburg position, $T 3=30 \mathrm{~min}$ after establishing carbon dioxide pneumoperitoneum and a steep Trendelenburg position, $T 4=60 \mathrm{~min}$ after establishing carbon dioxide pneumoperitoneum and a steep Trendelenburg position, $T 5=$ at the end of surgery after desufflation of pneumoperitoneum in the supine position propofol group and the sevoflurane group at all predetermined time points under general anesthesia $(66.3 \%$ vs. $67.7 \%, P=0.539$ at $\mathrm{T} 1 ; 65.1 \%$ vs. $66.1 \%, P=0.614$ at $\mathrm{T} 2$; $64.4 \%$ vs. $65.3 \%, P=0.698$ at T3; $64.3 \%$ vs. $65.9 \%, P=$ 0.470 at $\mathrm{T} 4 ; 65.1 \%$ vs. $68.4 \%, P=0.152$ at T5).

There was no significant difference in the duration of hospital stay between the propofol group and the sevoflurane group (7.7 days vs. 7.6 days, $P=0.635)$. In addition, postoperative neurologic complications did not occur in both groups.

\section{Discussion}

The sonographic ONSD of propofol anesthesia was significantly lower than that of sevoflurane anesthesia

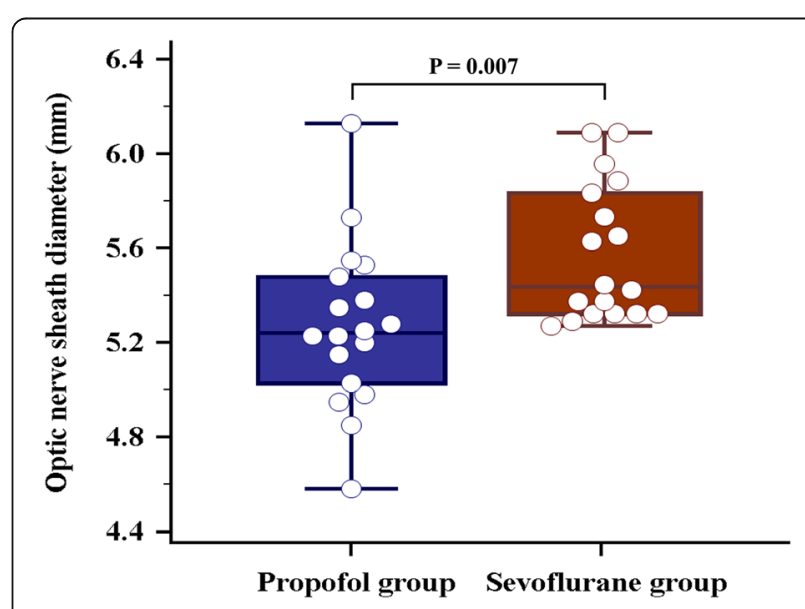

Fig. 2 Comparison of the optic nerve sheath diameters between the propofol group and the sevoflurane group at 60 min after carbon dioxide pneumoperitoneum and a steep Trendelenburg position 


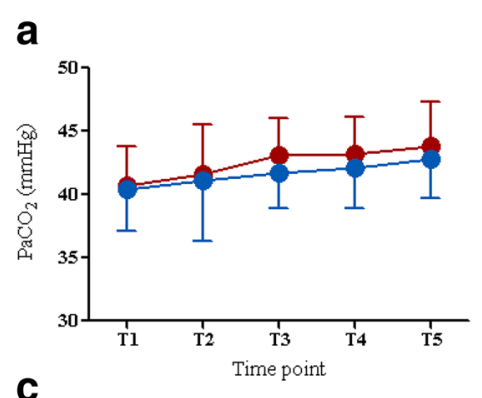

Sevoflurane group

Propofol group

b

C
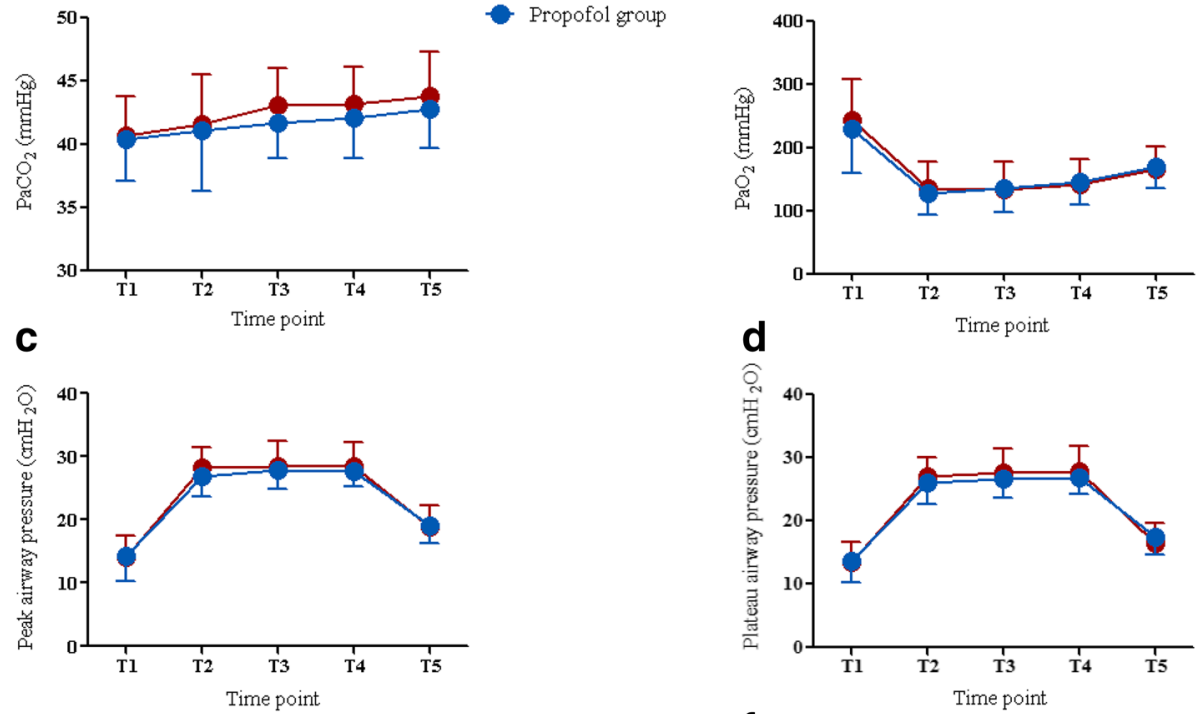

e

f
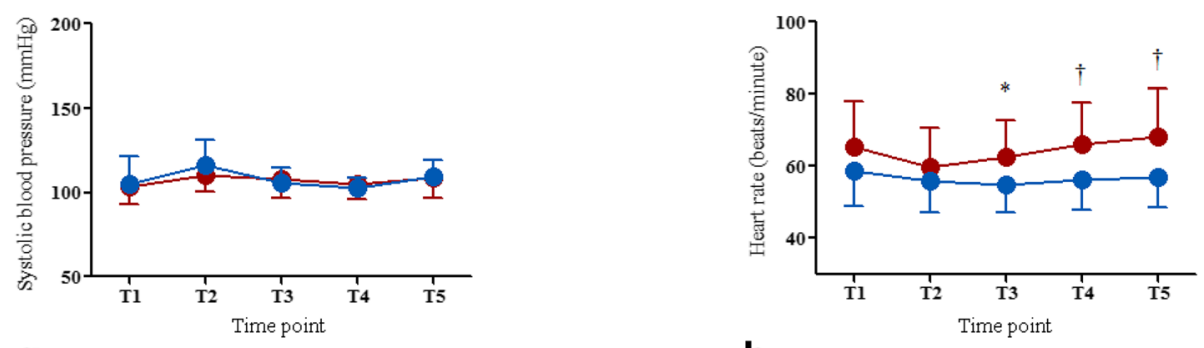

g

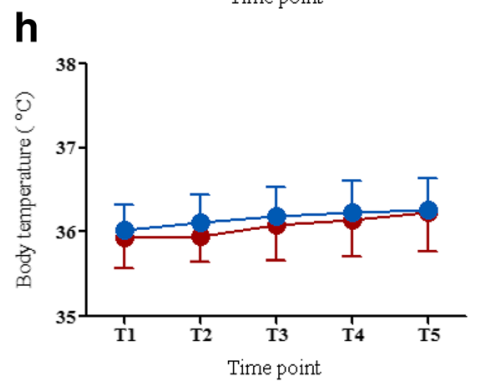

Fig. 3 Comparisons of $\mathrm{PaO}_{2}$ (a) $\mathrm{PaCO}_{2}$ (b) peak airway pressure (c) plateau airway pressure (d) systolic blood pressure (e) heart rate (f) pulse pressure variation $(\mathbf{g})$ and body temperature (h) between the propofol group (blue circle) and the sevoflurane group (red circle) during robot-assisted laparoscopic prostatectomy. Note that all parameters except heart rate do not significantly differ between the two groups. PaCO $=$ arterial carbon dioxide partial pressure, $\mathrm{PaO}_{2}=$ arterial oxygen partial pressure, $\mathrm{T} 1=10 \mathrm{~min}$ after anesthetic induction in the supine position, $\mathrm{T} 2=5 \mathrm{~min}$ after establishing carbon dioxide pneumoperitoneum and a steep Trendelenburg position, T3 = 30 min after establishing carbon dioxide pneumoperitoneum and a steep Trendelenburg position, T4 =60 min after establishing carbon dioxide pneumoperitoneum and a steep Trendelenburg position, and $\mathrm{T} 5=$ at the end of surgery after desufflation of pneumoperitoneum in the supine position. ${ }^{*}$ indicates $P<0.05$ between the two groups; + indicates $P<0.01$ between the two groups

60 min after establishing carbon dioxide pneumoperitoneum and a steep Trendelenburg position in prostate cancer patients who underwent RALP. In addition, the sonographic ONSDs increase continuously after establishing carbon dioxide pneumoperitoneum and a steep Trendelenburg position in both groups.

Anesthetics suppress the activity of electroencephalogram and reduce the cerebral metabolic rate. However, changes in cerebral metabolic rate and cerebral blood flow are inconstant and depends on how the anesthetic affects the cerebral vascular smooth muscle [16]. Sevoflurane has a dose-dependent effect on the vascular smooth muscle relaxation and intrinsic cerebral vasodilatory activity through the direct inhibition of several pathways. Therefore, cerebral blood flow increases significantly during sevoflurane anesthesia, and ICP can increase as a result $[10,17,18]$. However, propofol slows the activity of electroencephalogram, decreases the rate 
of consumption of adenosine, and reduces the cerebral metabolic rate $[8,19,20]$. Decreased cerebral metabolic rate reduces cerebral blood perfusion, which is known to reduce cerebral blood flow and ICP [21]. In addition, previous human and animal studies determined that propofol led to a progressive decrease in ICP [22-24]. In particular, ICP tended to decrease over time during the continuous administration of propofol. Farling et al. continuously administered propofol to head injury patients in intensive care and measured the ICP at multiple time points. They reported that ICP significantly decreased after $2 \mathrm{~h}$ of continuous administration [23]. Therefore, it could be expected that the difference in ICP between the two groups would gradually increase over time. In the present study, the difference in the ONSD between the two groups was not statistically significant at $\mathrm{T} 2$, but tended to differ between groups at T3. The ONSD at T4 was significantly different between the two groups. We consider that the continuous administration of propofol had a beneficial effect on ICP during RALP.

Many studies have determined that carbon dioxide pneumoperitoneum and a steep Trendelenburg position could increase ONSD as a surrogate for ICP [15, 25-27]. The pneumoperitoneum and Trendelenburg position may disturb cerebral venous drainage due to increased intrathoracic pressure, and may lead to a subsequent increase in ICP [28-30]. Moreover, carbon dioxide can increase intracranial vascular perfusion and elevate ICP [31-33]. In the present study, ONSD increased steadily from the induction of carbon dioxide pneumoperitoneum and steep Trendelenburg position in both groups. A previous study reported that ONSD increased immediately after establishing pneumoperitoneum and a steep Trendelenburg position, but then remained unchanged [25]. The ongoing increase in ONSD in our study is thought to be due at least in part to an age-related difference. Based on a previous study regarding ONSD change in patients during RALP [34], the ONSD tended to increase continuously over time in patients greater than 63 years of age after establishing pneumoperitoneum and a steep Trendelenburg position. However, in patients less than 63 years of age, ONSD decreased over the course of pneumoperitoneum and a steep Trendelenburg position [34]. The authors explained that younger patients had better autoregulation of ONSD or ICP during pneumoperitoneum and the Trendelenburg position. In the present study, the average age of the propofol group was $66.1 \pm 7.2$ years, and that of the sevoflurane group was $63.6 \pm 7.9$ years. Therefore, it seems likely that the ability to compensate for ICP changes might be reduced, and so ONSD increased continuously over time during surgery.

ONSD measurement using ultrasonography is a simple, non-invasive technique for ICP assessment. Previous studies have reported that sonographic measurement of
ONSD strongly correlates with measurement performed by inserting an invasive catheter into one of the lateral ventricles or the brain parenchyma in various clinical situations, including RALP [11, 15, 35, 36]. Intracranial hypertension is defined as ICP greater than $20 \mathrm{mmHg}$ [37], and the cut off value of the ONSD for intracranial hypertension is known to be $4.8-5.2 \mathrm{~mm}$ [38-41]. In the present study, ONSD was measured as $5.27 \pm 0.35 \mathrm{~mm}$ in the propofol group and $5.57 \pm 0.28 \mathrm{~mm}$ in the sevoflurane group at $60 \mathrm{~min}$ after establishing pneumoperitoneum and the Trendelenburg position. Because this is a situation in which intracranial hypertension might be suspected, it is important to minimize the increase in ONSD during RALP.

The present study has the following limitations. We could not measure ICP because the difficulty and invasiveness of the procedure made it impossible to be carried out in non-neurosurgical patients. However, sonographic measurement of ONSD is a non-invasive technique and has been shown to accurately reflect increases in ICP [42, 43]. Also, we did ONSD was not measured immediately after establishing carbon dioxide pneumoperitoneum and a steep Trendelenburg position. Instead, ONSD was measured at 5 min after establishing pneumoperitoneum and the Trendelenburg position, a time point that can adequately reflect the immediate change of ONSD during RALP.

\section{Conclusion}

We found that ONSD was significantly lower during propofol anesthesia than during sevoflurane anesthesia 60 min after carbon dioxide pneumoperitoneum and a steep Trendelenburg position in robotic prostatectomy patients. Our results suggest that propofol anesthesia might be used effectively to minimize intraoperative ICP changes in prostate cancer patients who are undergoing RALP using pneumoperitoneum and the Trendelenburg position.

\section{Abbreviations \\ ICP: Intracranial pressure; ONSD: Optic sheath nerve diameter; $\mathrm{PaCO}_{2}$ : Arterial carbon dioxide partial pressure; $\mathrm{PaO}_{2}$ : Arterial oxygen partial pressure; \\ RALP: Robot-assisted laparoscopic prostatectomy; T1: 10 min after anesthetic induction in the supine position,; T2: 5 min after establishing carbon dioxide pneumoperitoneum and a steep Trendelenburg position (45-degree incline); T3: 30 min after establishing carbon dioxide pneumoperitoneum and a steep Trendelenburg position; T4: 60 min after establishing carbon dioxide pneumoperitoneum and a steep Trendelenburg position; T5: At the end of surgery after desufflation of pneumoperitoneum in the supine position}

\section{Acknowledgements \\ The authors thank Dr. Joon Seo Lim from the Scientific Publications Team at Asan Medical Center for his editorial assistance in preparing this article.}

Availability of data and materials

The datasets used and analyzed during the current study are available from the corresponding author on reasonable request. 


\section{Authors' contributions}

YKK and SSC conceived and coordinated the study. JY, JH Hong, JYP, JH Hwang and YKK performed the experiments. JY, SSC and YKK collected and analyzed the data. JY wrote the manuscript. YKK and SSC edited the manuscript. All authors read and approved the final manuscript.

\section{Ethics approval and consent to participate}

The study protocol was approved by the Asan Medical Center Institutional Review Board (approval number: 2017-1011). Written informed consent was obtained from all patients.

\section{Competing interests}

The authors declare that they have no competing interests.

\section{Publisher's Note}

Springer Nature remains neutral with regard to jurisdictional claims in published maps and institutional affiliations.

\section{Author details}

'Department of Anesthesiology and Pain Medicine, Asan Medical Center, University of Ulsan College of Medicine, 88, Olympic-ro 43-gil, Songpa-gu, Seoul 05505, Republic of Korea. ${ }^{2}$ Department of Urology, Asan Medical Center, University of Ulsan College of Medicine, Seoul 05505, Republic of Korea. ${ }^{3}$ Department of Occupational and Environmental Medicine, Hallym University Sacred Heart Hospital, 22, Kwanpying-ro 170-gil, Dongan-gu, Anyang 14068, Republic of Korea.

\section{Received: 29 January 2018 Accepted: 22 May 2018}

\section{Published online: 20 June 2018}

\section{References}

1. Binder J, Kramer W. Robotically-assisted laparoscopic radical prostatectomy. BJU Int. 2001:87(4):408-10.

2. Rassweiler J, Hruza M, Teber D, Su LM. Laparoscopic and robotic assisted radical prostatectomy-critical analysis of the results. Eur Urol. 2006;49(4): 612-24

3. Berryhill R Jr, Jhaveri J, Yadav R, Leung R, Rao S, El-Hakim A, Tewari A. Robotic prostatectomy: a review of outcomes compared with laparoscopic and open approaches. Urology. 2008;72(1):15-23.

4. Gainsburg DM. Anesthetic concerns for robotic-assisted laparoscopic radical prostatectomy. Minerva Anestesiol. 2012;78(5):596-604

5. Halverson A, Buchanan R, Jacobs L, Shayani V, Hunt T, Riedel C, Sackier J. Evaluation of mechanism of increased intracranial pressure with insufflation. Surg Endosc. 1998:12(3):266-9.

6. Park EY, Koo BN, Min KT, Nam SH. The effect of pneumoperitoneum in the steep Trendelenburg position on cerebral oxygenation. Acta Anaesthesiol Scand. 2009;53(7):895-9.

7. Moss E, Price DJ. Effect of propofol on brain retraction pressure and cerebral perfusion pressure. Br J Anaesth. 1990;65(6):823-5.

8. Alkire MT, Haier RJ, Barker SJ, Shah NK, Wu JC, Kao YJ. Cerebral metabolism during propofol anesthesia in humans studied with positron emission tomography. Anesthesiology. 1995;82(2):393-403.

9. Bundgaard $H$, von Oettingen $G$, Larsen KM, Landsfeldt $U$, Jensen KA, Nielsen E, Cold GE. Effects of sevoflurane on intracranial pressure, cerebral blood flow and cerebral metabolism. A dose-response study in patients subjected to craniotomy for cerebral tumours. Acta Anaesthesiol Scand. 1998;42(6) 621-7.

10. Matta BF, Heath KJ, Tipping K, Summors AC. Direct cerebral vasodilatory effects of sevoflurane and isoflurane. Anesthesiology. 1999;91(3):677-80.

11. Dubost C, Le Gouez A, Jouffroy V, Roger-Christoph S, Benhamou D, Mercier FJ, Geeraerts T. Optic nerve sheath diameter used as ultrasonographic assessment of the incidence of raised intracranial pressure in preeclampsia: a pilot study. Anesthesiology. 2012;116(5):1066-71.

12. Saghaei M. Random allocation software for parallel group randomized trials. BMC Med Res Methodol. 2004;4:26.

13. Marsh B, White M, Morton N, Kenny GN. Pharmacokinetic model driven infusion of propofol in children. Br J Anaesth. 1991;67(1):41-8.

14. Minto CF, Schnider TW, Egan TD, Youngs E, Lemmens HJ, Gambus PL, Billard V, Hoke JF, Moore KH, Hermann DJ, et al. Influence of age and gender on the pharmacokinetics and pharmacodynamics of remifentanil. I Model development. Anesthesiol. 1997:86(1):10-23.
15. Chin JH, Seo H, Lee EH, Lee J, Hong JH, Hwang JH, Kim YK. Sonographic optic nerve sheath diameter as a surrogate measure for intracranial pressure in anesthetized patients in the Trendelenburg position. BMC Anesthesiol. 2015;15:43.

16. Rehberg B, Bouillon T, Zinserling J, Hoeft A. Comparative pharmacodynamic modeling of the electroencephalography-slowing effect of isoflurane, sevoflurane, and desflurane. Anesthesiology. 1999;91(2):397-405.

17. Chui J, Mariappan R, Mehta J, Manninen P, Venkatraghavan L. Comparison of propofol and volatile agents for maintenance of anesthesia during elective craniotomy procedures: systematic review and meta-analysis. Can J Anaesth. 2014:61(4):347-56.

18. Talke P, Caldwell JE, Richardson CA. Sevoflurane increases lumbar cerebrospinal fluid pressure in normocapnic patients undergoing transsphenoidal hypophysectomy. Anesthesiology. 1999;91(1):127-30.

19. Oshima T, Karasawa F, Satoh T. Effects of propofol on cerebral blood flow and the metabolic rate of oxygen in humans. Acta Anaesthesiol Scand. 2002:46(7):831-5.

20. Illievich UM, Petricek W, Schramm W, Weindlmayr-Goettel M, Czech T, Spiss CK. Electroencephalographic burst suppression by propofol infusion in humans: hemodynamic consequences. Anesth Analg. 1993;77(1):155-160.

21. Van Hemelrijck J, Van Aken H, Plets C, Goffin J, Vermaut G. The effects of propofol on intracranial pressure and cerebral perfusion pressure in patients with brain tumors. Acta Anaesthesiol Belg. 1989:40(2):95-100.

22. Mangez JF, Menguy E, Roux P. Sedation by constant-rate propofol in the head-injured patient. Preliminary results. Ann Fr Anesth Reanim. 1987;6(4): $336-7$.

23. Farling PA, Johnston JR, Coppel DL. Propofol infusion for sedation of patients with head injury in intensive care. A preliminary report. Anaesthesia 1989:44(3):222-6.

24. Kahveci FS, Kahveci N, Alkan T, Goren B, Korfali E, Ozluk K. Propofol versus isoflurane anesthesia under hypothermic conditions: effects on intracrania pressure and local cerebral blood flow after diffuse traumatic brain injury in the rat. Surg Neurol. 2001;56(3):206-14.

25. Kim MS, Bai SJ, Lee JR, Choi YD, Kim YJ, Choi SH. Increase in intracrania pressure during carbon dioxide pneumoperitoneum with steep trendelenburg positioning proven by ultrasonographic measurement of optic nerve sheath diameter. J Endourol. 2014;28(7):801-6.

26. Whiteley JR, Taylor J, Henry M, Epperson TI, Hand WR. Detection of elevated intracranial pressure in robot-assisted laparoscopic radical prostatectomy using ultrasonography of optic nerve sheath diameter. J Neurosurg Anesthesiol. 2015;27(2):155-9.

27. Robba C, Cardim D, Donnelly J, Bertuccio A, Bacigaluppi S, Bragazzi N, Cabella B, Liu X, Matta B, Lattuada M, et al. Effects of pneumoperitoneum and Trendelenburg position on intracranial pressure assessed using different non-invasive methods. Br J Anaesth. 2016:117(6):783-91.

28. Fahy BG, Barnas GM, Nagle SE, Flowers JL, Njoku MJ, Agarwal M. Effects of Trendelenburg and reverse Trendelenburg postures on lung and chest wall mechanics. J Clin Anesth. 1996;8(3):236-44.

29. Guerci AD, Shi AY, Levin H, Tsitlik J, Weisfeldt ML, Chandra N. Transmission of intrathoracic pressure to the intracranial space during cardiopulmonary resuscitation in dogs. Circ Res. 1985:56(1):20-30.

30. Hariri RJ, Firlick AD, Shepard SR, Cohen DS, Barie PS, Emery JM 3rd, Ghajar JB. Traumatic brain injury, hemorrhagic shock, and fluid resuscitation: effects on intracranial pressure and brain compliance. J Neurosurg. 1993;79(3): 421-7.

31. Harper AM, Glass HI. Effect of alterations in the arterial carbon dioxide tension on the blood flow through the cerebral cortex at normal and low arterial blood pressures. J Neurol Neurosurg Psychiatry. 1965;28(5):449-52.

32. Harper AM. Physiology of cerebral bloodflow. Br J Anaesth. 1965;37:225-35.

33. Lassen NA, Christensen MS. Physiology of cerebral blood flow. Br J Anaesth. 1976;48(8):719-34

34. Blecha $S$, Harth M, Schlachetzki F, Zeman F, Blecha C, Flora P, Burger M, Denzinger S, Graf BM, Helbig H, et al. Changes in intraocular pressure and optic nerve sheath diameter in patients undergoing robotic-assisted laparoscopic prostatectomy in steep 45 degrees Trendelenburg position. BMC Anesthesiol. 2017:17(1):40.

35. Geeraerts T, Merceron S, Benhamou D, Vigue B, Duranteau J. Non-invasive assessment of intracranial pressure using ocular sonography in neurocritical care patients. Intensive Care Med. 2008;34(11):2062-7.

36. Jun IJ, Kim M, Lee J, Park SU, Hwang JH, Hong JH, Kim YK. Effect of mannitol on Ultrasonographically measured optic nerve sheath diameter as 
a surrogate for intracranial pressure during robot-assisted laparoscopic prostatectomy with pneumoperitoneum and the Trendelenburg position. J Endourol. 2018; https://doi.org/10.1089/end.2017.0828.

37. Bratton SL, Chestnut RM, Ghajar J, McConnell Hammond FF, Harris OA, Hartl R, Manley GT, Nemecek A, Newell DW, Rosenthal G, et al. Guidelines for the management of severe traumatic brain injury. VI. Indications for intracranial pressure monitoring. J Neurotrauma. 2007;24(Suppl 1):S37-44.

38. Blaivas M, Theodoro D, Sierzenski PR. Elevated intracranial pressure detected by bedside emergency ultrasonography of the optic nerve sheath. Acad Emerg Med. 2003;10(4):376-81.

39. Tayal VS, Neulander M, Norton HJ, Foster T, Saunders T, Blaivas M. Emergency department sonographic measurement of optic nerve sheath diameter to detect findings of increased intracranial pressure in adult head injury patients. Ann Emerg Med. 2007:49(4):508-14.

40. Moretti R, Pizzi B. Optic nerve ultrasound for detection of intracranial hypertension in intracranial hemorrhage patients: confirmation of previous findings in a different patient population. J Neurosurg Anesthesiol. 2009; 21(1):16-20

41. Rajajee V, Vanaman M, Fletcher JJ, Jacobs TL. Optic nerve ultrasound for the detection of raised intracranial pressure. Neurocrit Care. 2011;15(3):506-15.

42. Kristiansson H, Nissborg E, Bartek J Jr, Andresen M, Reinstrup P, Romner B. Measuring elevated intracranial pressure through noninvasive methods: a review of the literature. J Neurosurg Anesthesiol. 2013;25(4):372-85.

43. Strumwasser A, Kwan RO, Yeung L, Miraflor E, Ereso A, Castro-Moure F, Pate A, Sadjadi J, Victorino GP. Sonographic optic nerve sheath diameter as an estimate of intracranial pressure in adult trauma. J Surg Res. 2011;170(2): $265-71$

\section{Ready to submit your research? Choose BMC and benefit from}

- fast, convenient online submission

- thorough peer review by experienced researchers in your field

- rapid publication on acceptance

- support for research data, including large and complex data types

- gold Open Access which fosters wider collaboration and increased citations

- maximum visibility for your research: over $100 \mathrm{M}$ website views per year 